\title{
Indications from space geodesy, gravimetry and seismology for slow Earth expansion at present - comment on "The Earth expansion theory and its transition from scientific hypothesis to pseudoscientific belief"' by Sudiro (2014)
}

\author{
Matthew R. Edwards \\ Gerstein Science Information Centre, University of Toronto, Toronto, M5S 1A5, Canada \\ Correspondence to: Matthew R. Edwards (matt.edwards@utoronto.ca)
}

Received: 9 November 2016 - Accepted: 9 December 2016 - Published: 22 December 2016

\begin{abstract}
In a recent article in this journal, Paolo Sudiro (2014) considered the long history of the expanding Earth theory and its recent descent into what he termed "pseudoscientific belief". The expanding Earth theory contends that the radius of the Earth was once one-half to two-thirds of its current value, with the Earth's continents forming a continuous sialic cover over the Earth. The theory has had two main variants: slow expansion at about $0.5 \mathrm{~mm} \mathrm{yr}^{-1}$ radial increase since the time of Earth's formation and fast expansion at about $5 \mathrm{~mm} \mathrm{yr}^{-1}$ since the Triassic. Focusing on Maxlow's model, Sudiro thoroughly addresses the possibly insurmountable difficulties of the fast version, such as an improbably high density and surface gravity prior to $200 \mathrm{Ma}$. He omits, however, any discussion of the slow expansion model, which has a longer history and far fewer theoretical difficulties. Moreover, recent evidence from space geodesy, gravimetry and seismology indicates that the Earth at present may be slowly expanding at $0.1-0.4 \mathrm{~mm} \mathrm{yr}^{-1}$. It is concluded that Sudiro's obituary of the expanding Earth theory as a whole must be considered premature at this time.
\end{abstract}

\section{Introduction}

In this journal, Paolo Sudiro (2014) recently made an extremely critical assessment of a theory that had already gained considerable notoriety: the expanding Earth theory. This theory has waxed and waned in popularity for more than a century, but with Sudiro's assessment - that it carries on only as a form of "pseudoscientific belief" - it would seemingly have found its nadir. The expanding Earth theory holds that the Earth's radius was at one time $30-50 \%$ smaller than it is today, or even smaller in a few models. Its main impetus has always been the observation that on a smaller globe the continents could perhaps have interlocked to form a perfectly continuous sialic cover over the Earth (Fig. 1). In this theory, expansion of the Earth caused the continental crust to break up. The ocean basins represent new mantle and crust which rose up from below to fill in the gaps created between the dispersing continental blocks. The theory comes in many different forms and the complexities of the various models can be quite daunting. In broad terms, however, most of the discussion of the expanding Earth theory has focused on two main variants, fast expansion and slow expansion, each of which typically assumes that the Earth's radius before expansion was about $60 \%$ of its current radius.

The fast expansion model supposes expansion rates of about $5 \mathrm{~mm} \mathrm{yr}^{-1}$, typically commencing in the Triassic. This model dates back at least to the early 20th century in the work of Hilgenberg (1933; for a historical account, see Scalera and Braun, 2003). Hilgenberg's work was later brought to light by S. W. Carey, who was to become perhaps the most famous and influential exponent of the expanding Earth theory. For an introduction to the fast expansion model, Carey's works are still possibly the most engaging and informative (Carey, 1975, 1976, 1983, 1988). The fast expansion hypoth- 


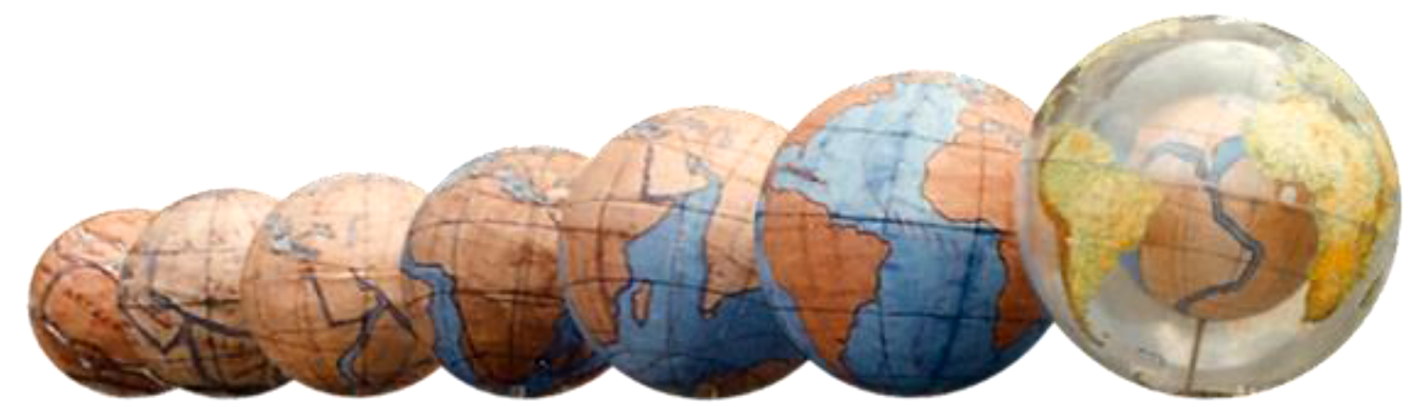

Figure 1. A series of "terrella" models constructed by Klaus Vogel showing various stages of Earth expansion. At the far right a globe with $55 \%$ present radius is shown within a transparent model of the present day Earth. The image was digitally retouched by James Maxlow from a photograph of Vogel's (courtesy of James Maxlow).

esis received a major boost in the 1960 s with the discovery that seafloor ages were nowhere greater than 200 million years. This finding seemed to confirm the expanding Earth premise that the basins were only late constructs in Earth's development and that, for much of its history, the Earth was covered by continental crust overlaid by a shallow sea (Heezen, 1960). The brief flirtation of some geologists with the fast expansion model arose because the concept of subduction was late to be added to the plate tectonics model. Once subduction was integrated, the main impetus for fast expansion quickly subsided. At the same time, more serious and persistent obstacles appeared on the geophysical side. Amongst these was the problem of Earth's rotation. If the Earth's radius were increasing at the fast expansion rate, then the changing moment of inertia of the Earth would have led to significant, observable slowing in the Earth's rotation over the last $200 \mathrm{Ma}$, well beyond the rate of slowing that has actually been observed (Weijermars, 1986; Williams, 2000). The Earth's density and also its surface gravity would also have been much larger in the Palaeozoic than observations appear to allow. Sudiro highlighted these aspects with particular reference to Maxlow's theory, in which the preexpansion Earth had a radius of only $1700 \mathrm{~km}$, or about $27 \%$ of its present radius (Maxlow, 2005, 2012). Sudiro termed Maxlow's Archean Earth a "dwarf earth", one in which all the geophysical problems of fast expansion find their most severe expression.

Sudiro also noted the requirement of fast expansion models for "exotic physics" to account for the huge quantities of energy and/or mass that were somehow added to the Earth over the last $200 \mathrm{Ma}$, evidence for which has again been lacking. Many proposals have been made to address the need for energy in expanding Earth models (for a general review, see Carey, 1975, 1976, pp. 445-460; Scalera, 2003). In fast expansion models, the focus has been on mechanisms involving a dramatic increase of mass, sometimes through condensation of gravitational quanta (e.g., Yarkovskii, 1889; Hilgenberg, 1933; Shneiderov, 1943, 1961; Blinov, 1983; Scalera, 2003; see also Edwards, 2002; Betelev, 2009). These mod- els tend to rely on separate hypotheses concerning gravity and inertia, for which insufficient evidence has been brought forward. They also tend to severely exacerbate the aforementioned problems concerning energy requirements, rotational inertia, surface gravity and density. Despite these serious problems, many recent proposals in the fast expansion mode have been made (Scalera, 1998, 2003, 2006; McCarthy, 2003; Vogel, 2012). Two recent and valuable compilations of theories and discussions centring mostly on fast expansion can be found in volumes which arose from workshops organized in Italy, in large part through the efforts of Giancarlo Scalera while at the Istituto Nazionale di Geofisica e Vulcanologia in Rome (Scalera and Jacob, 2003; Scalera et al., 2012).

By contrast, the slow expansion model features radial expansion at rates of only about $0.5 \mathrm{~mm} \mathrm{yr}^{-1}$ over several billions of years (Egyed, 1956, 1969; Creer, 1965; Dearnley, 1965, 1969). Like the fast expansion model, slow expansion had its peak of popularity in the 1960s, before being eclipsed by plate tectonics (for general discussions see Fairbridge, 1964; Carey, 1976, 1988; Kragh, 2015a, b). Unlike fast expansion, however, the slow expansion model could readily incorporate the central features of plate tectonics. The very same evidence used to justify plate tectonics, notably seafloor spreading at mid-ocean ridges (MORs) accompanied by crust removal at subduction zones, could also fit with slow Earth expansion (Weijermars, 1986). The main difference between the two lay in their relative rates of subduction. In slow expansion crust removal via subduction is less than the addition of new crust at MORs and it is this inequality which can lead to expansion. Also unlike fast expansion, a slowly expanding Earth cannot be ruled out on the basis of changing rates of Earth's rotation (Wesson, 1978, p. 140; Wesson, 1980, p. 65; Weijermars, 1986). Wesson concluded that the Earth's present rate of change in length of day of about $2 \mathrm{~ms}$ century $^{-1}$ is mainly due to tidal friction, but it could include a term due to variable $G$ and/or Earth expansion at a rate not greater than $0.6 \mathrm{~mm} \mathrm{yr}^{-1}$, i.e., at about the classic slow expansion rate. In addition, since the 
Earth would have expanded only about $100 \mathrm{~km}$ since the Triassic in slow expansion models, the effects of a changing surface gravity during that interval would be extremely difficult to detect. Weijermars (1986) also highlighted the continuing ability of slow expansion to explain the bimodal distribution of Earth's crust, i.e., a crust divided into upraised continental areas and depressed ocean basins, much better than plate tectonics does. As discussed below, the problem of a very high density for the pre-expansion Earth does remain, albeit in a far lesser degree than in fast expansion.

Considering the two principal variants, slow and fast expansion, a strange situation seems to have now arisen in geology. Despite its serious and perhaps unsolvable problems, it is the fast expansion model which is still most favoured by expansionists today. It is also the one most prevalent in the popular media, as exemplified in the so-called "growing Earth" contingent. Due to its many problems, the modernday fast expansionists have naturally become a choice target for geologists. However, because fast expansion has been so prevalent among expansion models, there has been a tendency amongst critics to lambaste the expanding Earth theory generally. Sudiro, while mentioning a few slow expansion theorists such as Creer (1965), omitted any actual discussion of the slow expansion model. He nonetheless characterized all modern expanding Earth proponents as engaging in a form of science fantasy. Indeed, there has been a general tendency among geologists not to recognize slow expansion as a separate model. Proponents of both plate tectonics and fast expansion tend to see recent slow expansion models, which incorporate some form of subduction, as being largely indistinguishable from plate tectonics. The middle theoretical ground that slow expansion occupies tends not to be recognized by either group. Slow expansion largely avoids the serious problems of fast expansion and at the same time possibly offers new clues to geology not found in standard plate tectonics.

The omission of slow expansion from recent discussions is doubly unfortunate since, for the first time, evidence drawn from space geodetic and gravimetric studies actually provides preliminary evidence of such expansion. The expansion rates found are in the range of $0.1-0.4 \mathrm{~mm} \mathrm{yr}^{-1}$ (Wu et al., 2011; Shen et al., 2011, 2015a, b), not far from the traditional slow expansion rate of $0.5 \mathrm{~mm} \mathrm{yr}^{-1}$. Much of the new work is being done in China, where it seems that a more open attitude towards the possibility of Earth expansion exists. In the following, we will review some of these new studies. We will then discuss other recent studies indicating that earthquakes and mantle plumes could be unexpected contributors to Earth expansion. The hour has gotten quite late for the expanding Earth theory, at least in western countries. Our goal is not to prove that the Earth is expanding or how, but merely to demonstrate that a reasonable case for a slowly expanding Earth can still be made - and thus that Sudiro's obituary and other such notices in geology and history of science journals are premature.

\section{Evidence for slow expansion from space geodetic and gravity field techniques}

From the foregoing considerations, it is not surprising that by the end of the 20th century the expanding Earth theory had faded nearly to oblivion, being kept barely alive by a handful of researchers, mostly in Europe, China and Australia. However, in the last few decades new space geodetic and gravimetric techniques have arisen which could at last answer the crucial question: is the Earth expanding at present? All previous assessments of possible expansion had been made using geological data taken at ground level. Such methods can infer developments spanning countless millennia but can say little about changes happening at present. By contrast, the new gravimetric and space geodetic techniques have already shed light on the expansion question. Much of the recent work has been done by Wen-Bin Shen and colleagues at Wuhan University, China.

The new space geodetic methods of estimating changes at the Earth's surface are technically highly complex, and only a brief description of them can be included here. The new methods include very-long-baseline interferometry (VLBI), Global Positioning System (GPS), satellite laser ranging (SLR) and Doppler Orbitography and Radiopositioning Integrated by Satellite (DORIS) (Altamimi et al., 2011; for recent reviews and discussions, see Altamimi and Collilieux, 2013). In general, data collected from all these systems are used to construct the International Terrestrial Reference System (ITRS), which is a geocentric system with its origin near the Earth's centre of mass (CM). The CM is the centre of mass of the entire Earth, including its oceans and atmosphere, and can thus move with respect to the origin due to redistribution of the Earth's mass. The tool that is actually used in practice is the International Terrestrial Reference Frame (ITRF), which is fixed in the crust, specifically in the system of tracking stations. A number of conventions have been adopted for the ITRF which create difficulties for measuring tiny effects such as seasonal hydrospheric loading of the hemispheres (for a discussion, see Drewes et al., 2013). A truly geocentric frame would instead fix the origin of the frame permanently in the Earth's CM. However, to estimate long-term trends in expansion and contraction the ITRF system alone can suffice (Shen et al., 2015a).

In using space geodetic data to measure changes in the Earth's radius, several other possible sources of error are present which need to be accounted for. First, the great majority of geodetic stations are located in the Northern Hemisphere, in part because the continental land masses themselves tend to be clustered there (see Fig. 2). Consequently, all stations cannot be weighted the same and ocean areas in particular tend to be neglected. This dependence on landbased stations to set up the ITRF potentially introduces a huge error in interpretation of results, as expansion could be occurring asymmetrically in one hemisphere or the other (Shen et al., 2015a). Secondly, many stations are located 


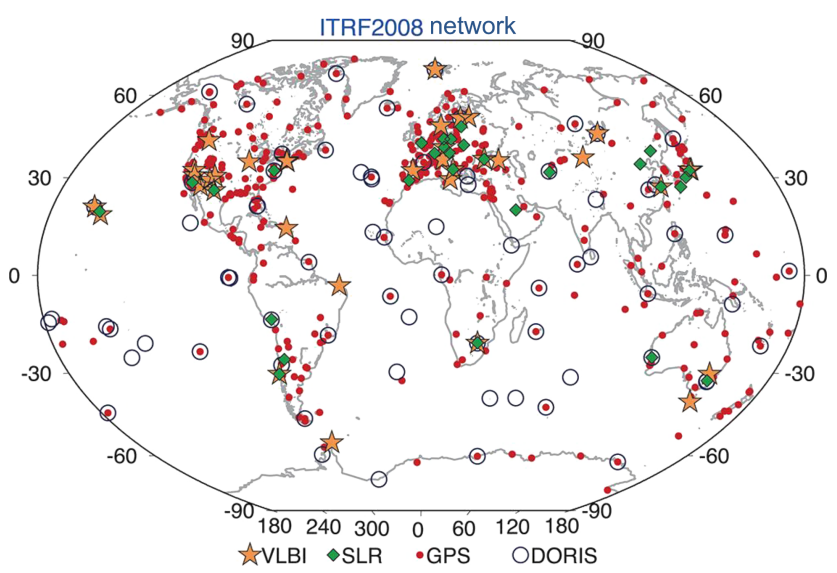

Figure 2. Full ITRF2008 network comprising 934 stations located at 580 sites, highlighting stations that are co-localized with GPS stations. The stations are highly clustered with 463 sites in the Northern Hemisphere and only 117 in the Southern Hemisphere. Many stations are situated on active orogens (from Altimimi, 2011).

on active orogen belts or at the edge of plate boundaries. Such stations are subject to steep vertical increases of up to $20 \mathrm{~cm} \mathrm{yr}^{-1}$, well in excess of the tiny rates likely to be seen in a slowly expanding Earth. A third significant problem concerns the effects of postglacial rebound (PGR). While this is only a small influence for most stations, it can be quite significant in more northerly ones, such as in Canada and Fennoscandia.

The application of these techniques to solving the Earth expansion problem was discussed by Shen et al. (2011). Taking the factors mentioned above into consideration, Shen et al. used space geodetic data collected from 629 VLBI, GPS, SLR and DORIS stations to estimate the annual change in the Earth's radius. The approach they used to measure expansion (or contraction) was to estimate the vertical (radial) velocities of every point on the Earth's surface from the averaged vertical velocities of a large number of observation stations scattered across the globe, each station weighted according to the accuracy of its measurements. Stations for which the absolute values of the vertical velocities were greater than $2 \mathrm{~cm} \mathrm{yr}^{-1}$ were not included in the study. The data covered a more than 10-year period under the frame of ITRF2008. The specific method they used was to construct a spherical Delaunay triangular irregular network (SDTIN), a network of non-overlapping triangles which touch along their edges and collectively cover the entire Earth's surface. The expansion rate was estimated from the representative vertical velocities of all the triangles. When the effects of PGR on individual stations were not included, they found a net expansion rate of $0.54 \mathrm{~mm} \mathrm{yr}^{-1}$. When PGR effects were included, the rate of expansion dropped to $0.24 \mathrm{~mm} \mathrm{yr}^{-1}$. Both values are close to the canonical slow expansion rate $0.5 \mathrm{~mm} \mathrm{yr}^{-1}$. Subsequently, Shen and colleagues (2015a) applied two other techniques - a virtual equator method and a gridding method
- to the same data and found expansion rates of 0.24 and $0.12 \mathrm{~mm} \mathrm{yr}^{-1}$ respectively.

Using similar data but different methods, Wu et al. (2011) found that the Earth was expanding at a lesser rate of $0.1 \pm$ $0.2 \mathrm{~mm} \mathrm{yr}^{-1}$. Since those authors considered this result to be statistically insignificant from zero, they concluded that no expansion was occurring at present. This conclusion is hard to justify, however, as their rate of $0.1 \mathrm{~mm} \mathrm{yr}^{-1}$ is $20 \%$ of the typical slow expansion rate and their error margin extends to values of up to $60 \%$ of that rate. It is possible, however, that $\mathrm{Wu}$ et al. only had the fast expansion model in mind when making their conclusion that the Earth is not expanding. The only expansionist author they cited is Carey, a noted fast expansion proponent. Shen et al. (2015a) later criticized the approach taken by $\mathrm{Wu}$ et al. of estimating multi-parameters (plate rotations, Love numbers, expansion, etc.) simultaneously. They stated that the accuracy of estimating the expansion rate is much higher when the vertical motions are explicitly isolated from the other parameters, as was done by Shen et al. (2011). For example, if CM had no motion but the Earth were in fact expanding, then this expansion would only have been reported in the study by $\mathrm{Wu}$ et al. as an uncertainty in the motion of CM.

Regarding CM motions, Argus (2012) noted that a change in the estimate of the velocity of CM towards the South Pole, for example, would result in a change in the velocity of all the sites by an equal amount in the opposite direction. Using SLR data from satellite LAGEOS, Argus found that the uncertainty of the $\mathrm{Z}$ velocity component (i.e., through the poles) could only be constrained to $\pm 0.9 \mathrm{~mm} \mathrm{yr}^{-1}$. This was consistent with a possible true velocity of CM of $0.5-$ $1.0 \mathrm{~mm} \mathrm{yr}^{-1}$ relative to that in ITFR2008. In the same vein, Shen et al. (2015a) noted that the origin of ITFR2008 is moving southward relative to that of ITFR2000 at the rate of $1.8 \mathrm{~mm} \mathrm{yr}^{-1}$. When this southward trend of CM was subtracted from the vertical velocities of all stations, the Southern Hemisphere was seen to be expanding at a rate of $0.71 \mathrm{~mm} \mathrm{yr}^{-1}$, while the Northern Hemisphere was contracting at $-0.44 \mathrm{~mm} \mathrm{yr}^{-1}$. They noted that these results were consistent with several earlier studies which indicate that the Earth is expanding asymmetrically in the Southern Hemisphere at present and also with the fact that seafloor spreading and hotspots are more concentrated in the Southern Hemisphere at this time. If the subtraction of CM velocity was not made, however, the situation was reversed. The Northern and Southern hemispheres would then be expanding and contracting respectively at rates of 0.46 and $-0.19 \mathrm{~mm} \mathrm{yr}^{-1}$. In either case, Shen et al. emphasized that the Earth as a whole was expanding over the last 2 decades at the rate of $0.2 \mathrm{~mm} \mathrm{yr}^{-1}$.

Changes in gravity at the Earth's surface can also be used to evaluate Earth expansion. Such changes can be caused by vertical displacements or redistribution of the Earth's mass (Collilieux and Altamimi, 2013). Presently, the uncertainty in absolute gravimeter (AG) measurements, if regarded as due 
to vertical displacements, is about $0.5 \mathrm{~mm} \mathrm{yr}^{-1}$. As was the case for the space geodetic data, this uncertainty is near the typical slow expansion value. Shen et al. (2011) used gravity data to test the expansion hypothesis from the monthly GRACE (Gravity Recovery And Climate Experiment) gravity fields and the secular variation rates of the three principle moments of inertia of the Earth $(\mathrm{A}, \mathrm{B}, \mathrm{C})$ and other parameters. They determined that the arithmetic mean of A, B and $\mathrm{C}$ is gradually increasing and concluded on that basis that the Earth is expanding at the rate of $0.17-0.21 \mathrm{~mm} \mathrm{yr}^{-1}$, which is similar to the rate of $0.24 \mathrm{~mm} \mathrm{yr}^{-1}$ that they found using space geodetic data in the same paper.

As noted above, a basic limitation on estimates of Earth expansion using space geodesy is that the tracking stations are situated primarily on large continental land masses in the Northern Hemisphere. To gain better estimates of global expansion it is necessary to include oceanic areas as well. While it is not yet possible to measure vertical velocities of the ocean crust directly, it is possible to measure precise changes in sea level rise using satellite altimetry. The problem here is that in addition to possible Earth expansion there are other known contributors to sea level rise, notably thermal expansion and glacial melting. Using the known sea level rise of $3.2 \pm 0.4 \mathrm{~mm} \mathrm{yr}^{-1}$ over the last 2 decades and using values of $1.8 \pm 0.5$ and $1.0 \pm 0.1 \mathrm{~mm} \mathrm{yr}^{-1}$ for glacial melting and thermal expansion respectively, Shen et al. (2015b) estimated Earth expansion in oceanic areas to be $0.4 \pm 0.67 \mathrm{~mm} \mathrm{yr}^{-1}$. While noting the low accuracy of this estimate, they averaged it with their earlier estimate of $0.24 \mathrm{~mm} \mathrm{yr}^{-1}$ vertical increase of the land surfaces (Shen et al., 2011) to obtain a global rate of expansion of $0.35 \pm 0.47 \mathrm{~mm} \mathrm{yr}^{-1}$ over the last 2 decades.

\section{Earthquakes and mantle plumes in Earth expansion}

Apart from these observations of possible Earth expansion at present, there is the question of how volume changes might be occurring within the Earth. Recently, Xu and Sun (2014) showed that earthquakes may have a part to play in these events. Noting earlier work by Chao and Gross (1987) connecting earthquakes to changes in the Earth's rotation, they showed that very powerful megathrust earthquakes cause the Earth to expand. Conversely, earthquakes along normal faults cause it to contract. Since the mega-quakes cumulatively have far more energy, their net finding is a slow expansion over the last 4 decades. Xu and Sun examined three megathrust quakes with magnitudes from 8.8 to 9.3 as models: the 2004 Sumatra quake, the 2010 Chile quake and the 2011 Tohoku-Oki quake. They then determined the cumulative volume change of the Earth from all earthquakes with magnitudes greater than 7.0 since 1960 and found an expansion rate of $0.011 \mathrm{~mm} \mathrm{yr}^{-1}$. More recently, Xu et al. (2016) concluded that historically accumulated earthquakes may have a total contribution of 0.02 to $0.06 \mathrm{~mm}^{-1}$ to the Earth expansion rate in the last 40 years.

These earthquake findings could mesh with a process of mountain building that has been envisioned by some proponents of the expanding Earth theory. Mechanisms of orogenesis in this theory typically have focused on the flattening forces exerted on the lithosphere as the Earth moves to a lower curvature with expansion (Hilgenberg, 1933; Cwojdzinski, 2003; Maxlow, 2005). As described by Pickford (1996a, b, 2003), orogenesis around ocean margins can also be seen as arising largely from compression due to the asymmetric expansion of the Earth in the ocean basins. Most MORs are located in the Southern Hemisphere and in the Pacific hemisphere. Assuming that the MORs reflect expansion in the underlying mantle, then the Southern and Pacific hemispheres are increasing in volume relative to the Northern and "non-Pacific" hemispheres. Gravity acts to keep the Earth's shape spherical, however, and this causes the crust of the expanding hemisphere to override or underride that of the other hemisphere. The resulting upward forces might then lead to orogenesis, while downward ones could cause the crust to be pulled down into the mantle at Benioff-Wadati zones. Seen in this light, the apparent small expansion related to earthquakes can possibly be seen as just a small fraction of the overall expansion, the fraction that is connected with uplift of continental land masses near compressional zones. Continental areas in the north, including most of Europe and North America, are far from such zones. For those masses the primary mode of uplift must be different. At the same time other continents, like Africa and Antarctica, are on their own plates. The MORs surrounding these continents can be likened to thermal expansion joints on bridges, facilitating uplift without compression. On this point, the lack of subduction around the African and Antarctic plates has been seen as one of the most persuasive arguments for an expanding Earth (Carey, 1988, p. 176; Nunan, 1988).

At the same time, other recent studies in seismology may possibly shed light on the deeper mechanism of expansion. Previously, many authors have tried to link expansion to some type of phase change process within the Earth (Jordan, 1971, pp. 118-142; Pickford, 2003; for a discussion, see Carey, 1975, 1976, pp. 445-460). Marchal (1996, p. 554; Pickford, 2003) supposed that the entire lower mantle and possibly the upper mantle as well were formed from the liquid outer core, which got progressively smaller over time. Since the outer core is roughly twice as dense as the mantle, an expansion of the Earth would then be implied. Using Ramsey's assumption that the mantle and the liquid core are just two phases of the same material, Marchal estimated that the Earth's initial volume prior to the existence of any mantle could have been as low as $58 \%$ of its present value. This would imply an initial Earth radius of about $0.8 R_{\mathrm{E}}$.

Intriguingly, recent findings on mantle plumes by French and Romanowicz (2015) may offer new support for this conjecture. Using a new whole-mantle seismic imaging tech- 


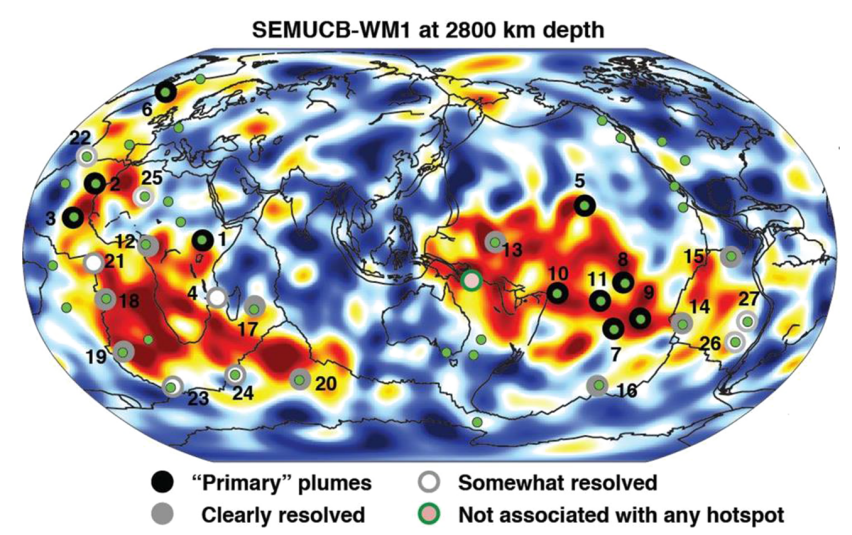

Figure 3. Mantle plume-hotspot connection. In the FrenchRomanowicz study, most of the known volcanic hotspots were found to be linked to plumes of hot rock (red) rising from the two large low shear velocity provinces (LLSVPs) situated at the CMB, one under the central Pacific and the other under Africa (courtesy UC Berkeley Media Relations).

nique (termed SEMUCB-WM1), French and Romanowicz found evidence for 28 deep mantle plumes rising from the core-mantle boundary (CMB) (Fig. 3). Their study follows earlier ones indicating the likely existence of such deeply extending plumes, first postulated by Morgan (1971) (e.g., Zhao, 2007; for reviews, see Koppers, 2011; Kerr, 2013). Almost all the plumes were connected with known surface hotspots. The plumes were very large, some $600-800 \mathrm{~km}$ in diameter, implying a much greater capacity to carry heat and mass than had previously been supposed. The plumes also rise in a nearly vertical fashion from the $\mathrm{CMB}$, not what would be expected if vigorous convection of the lower mantle were present (see Hand, 2015). Indeed, there had already been evidence that descending lithospheric slabs stall out near the $1000 \mathrm{~km}$ depth (Fukao et al., 2013). Lastly, pinching and shearing in the plumes as they reached the $1000 \mathrm{~km}$ depth suggested that the plumes are thermochemical plumes, i.e., composed of different material than the surrounding mantle (for a discussion of thermochemical plumes, see Kumagai et al., 2008). The thermochemical properties could be consistent with a contribution of light elements from the core, as proposed in some models (e.g., Kuzmin and Yarmolyuk, 2016). Connecting deep mantle plumes more precisely with a core-to-mantle conversion mechanism for Earth expansion can readily be achieved as follows. If it is supposed that subducting slabs descend only to about the $1000 \mathrm{~km}$ depth, for instance, then the total mass that is rising in plumes up to that depth from the CMB is not balanced by a return downward flow of mass towards the CMB in subducting slabs. Due to the lower pressures found at the $1000 \mathrm{~km}$ depth compared to those near the CMB, however, the plume minerals newly crystallizing there would have much lower densities than minerals near the CMB. The volume of the mantle would of necessity increase.
Could these deep mantle plumes also carry enough energy to drive expansion? The principal barrier to contemplating any kind of Earth expansion is the huge amount of energy required to increase the gravitational potential energy of the Earth. Burša and Hovorková (1994), for example, found that the minimum amount of energy needed to raise the Earth's radius from $60 \%$ of $R_{\mathrm{E}}$ up to $R_{\mathrm{E}}$ is $\Delta E=7 \times 10^{31} \mathrm{~J}$. Over the Earth's duration $T=4.5$ billion years and with an expansion rate of $0.5 \mathrm{~mm} \mathrm{yr}^{-1}$, the amount of energy steadily required to increase the Earth's radius would be $\Delta E / T=490 \mathrm{TW}$ (terawatts $=10^{12} \mathrm{~W}$ ). By contrast the rate of heat emission measured over all of the Earth's surface is currently estimated to be only about 44 TW. On this point, however, Chen (2000) thought that Earth expansion was more likely to have gradually attenuated over time. Using a mathematical model, Chen concluded that if the Earth's average expansion since $4300 \mathrm{Ma}$ years ago was $0.4 \mathrm{~mm} \mathrm{yr}^{-1}$, then its current rate of expansion might be only about $0.1 \mathrm{~mm} \mathrm{yr}^{-1}$. Significantly, this value is the same as that measured by Wu et al. (2011) through space geodetic data, as was mentioned above. For a rate of $0.1 \mathrm{~mm} \mathrm{yr}^{-1}$ the energy required for expansion at present would then be about $98 \mathrm{TW}$, still about double the Earth's surface heat flow of 44 TW. However, the plumes in the French and Romanowicz study are so large - with diameters as much as 3 times larger than hitherto believed - that they might conceivably carry enough energy to drive Chen's slow expansion.

If the deep mantle plumes are the major carriers of expansion energy, what could be the ultimate source of this energy? Many and diverse forms of expansion energy have previously been posited. Many involve mass increase, as noted above, or Dirac's notion of a decreasing gravitational constant (Dirac, 1937; Jordan, 1962, 1971; for reviews, see Wesson, 1978, 1980; Kragh, 2015a, b). The latter proposals fell to ground when no observational evidence for a decreasing $G$ could be found (e.g., Uzan, 2003). Another mechanism with a cosmological tie was proposed by the author (Edwards, 2006, 2012a, b, 2014). Here it was proposed that the internal gravitational potential energy of a mass or system of masses, $U$, is converted to photons and heat at a rate given by $-U H_{0}$. Evidence for such heating was given in systems ranging in size from planets to supermassive black holes to the universe as a whole. In the case of the Earth, the heat produced would be more than sufficient to drive slow Earth expansion. This mechanism notably does not involve any type of mass increase, as was stated by Sudiro.

Despite the foregoing considerations, the pre-expansion density of the Earth remains a serious unresolved issue for the slow Earth expansion hypothesis. A sphere with uniform density has a density inversely proportional to $R^{3}$. The average density of the Earth is $5.5 \mathrm{gm} \mathrm{cm}^{-3}$. If the primitive radius was only $0.8 R_{\mathrm{E}}$, as in the Marchal scenario, the initial density would have been about $10.7 \mathrm{gm} \mathrm{cm}^{-3}$. This value is comparable to that found in the liquid outer core, and so is perhaps geophysically plausible. However, if the Earth 
started with a radius of only $0.6 R_{\mathrm{E}}$, as often used in both fast or slow expansion models, its average density would initially have been about $25 \mathrm{gm} \mathrm{cm}^{-3}$. Such a high density seems unrealistic, as it is over twice as great as that of the outer core, and far greater than any other planet or moon in the solar system. Sudiro examined this density problem in considerable detail. He used a $50 \%$ rather than the more conventional $60 \%$ pre-expansion globe in his analysis, however, which had the effect of significantly exaggerating the problem.

Would expansion from a larger, $80 \%$ pre-expansion globe still fit with the expanding Earth theory? The central pillar of the expanding Earth theory has always been the idea that continental crust at one time completely covered the whole globe. That idea stems from the notion that on a cooling, initially molten Earth, the first solid structure to be formed would have been a uniform sialic crust. It is in a sense the historical raison d'être of the expanding Earth theory - along with its explanation of how the dichotomy in the Earth's crust evolved. However, is it really indispensable? A non-rotating, cooling body might well be expected to develop a uniform crust, but a rapidly rotating body such as the early Earth might not be. In this case, perhaps continental-type crust and ocean-type crust could have coexisted from very early on. In that case, perhaps Owen's configuration at $200 \mathrm{Ma}-$ a continental hemisphere and an oceanic hemisphere on an $80 \%$ globe - might be transposed back in time to the very early Archean (Owen, 1976, 1983). Suppose that this state existed at $4 \mathrm{Ga}$ and that expansion proceeded linearly since then. From an initial radius of $80 \% R_{\mathrm{E}}$, this would give a steady radial increase of $0.32 \mathrm{~mm} \mathrm{yr}^{-1}$. This rate would be in line with the current rates of expansion found by Shen et al. (2011, 2015a) or, if Chen's notion of exponentially limited expansion is included, the expansion rate could be scaled back to as little as $0.05-0.07 \mathrm{~mm} \mathrm{yr}^{-1}$. The rate of present energy consumption required in that case would then only be about 50-70 TW, perhaps more easily within the range at which plumes might be able to deliver it. In this scenario the continents could have remained partially attached until the Mesozoic. Such tight clustering of the continents throughout Earth's early history would perhaps be consistent with a model of supercontinent evolution proposed by Piper (1982, 2001, 2013).

\section{Conclusions}

In the foregoing, it has been our purpose to show that the slow variant of the expanding Earth theory, unlike most if not all the fast variants, is still within the realm of real science. All the matters discussed herein - the measured slow expansion of the Earth in space geodetic and gravimetric studies, the possible capacity of deep mantle plumes to carry the energy and mass needed for slow expansion and the generation of sufficient expansion energy within the Earth - require further substantiation, both in theory and observation. However, un- til such time as observations and theory prove conclusively otherwise on these matters, it is simply prudent for geologists and historians of geology alike to hold off on blanket obituaries of the expanding Earth theory. The assessment of Sudiro that all the modern proponents of Earth expansion are engaging in pseudoscience is unwarranted.

The expanding Earth theory has travelled far too long without a definitive answer to the central question: is the Earth expanding? That situation may be about to change. Geology is poised at a crossroads. Very soon space geodetic techniques may be able to detect definitively an increase in the Earth's radius of as little as $0.1 \mathrm{~mm} \mathrm{yr}^{-1}$. The confirmation of such a tiny change would be an astonishing technical feat in its own right. What is more astonishing is that it could transform geology forever.

Acknowledgements. I wish to thank Pascal Richet and Gregory Good for their kind and most valuable assistance.

Edited by: P. Richet

\section{References}

Altamimi, Z. and Collilieux, X. (Eds.): Reference frames for applications in geosciences, International Association of Geodesy Symposia 138, Springer-Verlag, Berlin, 2013.

Altamimi, Z., Collilieux, X., and Métivier, L.: ITRF2008: an improved solution of the international terrestrial reference frame, J. Geod., 85, 457-473, 2011.

Argus, D. F.: Uncertainty in the velocity between the mass center and surface of Earth, J. Geophys. Res., 117, B10405, doi:10.1029/2012JB009196, 2012.

Betelev, N. P.: The concept of an expanding Earth, J. Volcanol. Seismol., 3, 355-362, 2009.

Blinov, V. F.: Problem of the evolution of the hydrosphere and the expansion of the Earth, Int. Geol. Rev., 25, 334-344, 1983.

Burša, M. and Hovorková, O.: Expanding Earth hypothesis and the Earth's gravitational potential energy, Stud. Geophys. Geod., 38, 235-245, 1994.

Carey, S. W.: The expanding Earth - an essay review, Earth-Sci. Rev., 11, 105-143, 1975.

Carey, S. W.: The Expanding Earth, Amsterdam, Elsevier, 488 pp., 1976.

Carey, S. W. (Ed): The necessity of Earth expansion, in: Expanding Earth Symposium, University of Tasmania, Sidney, 375-393, 1983.

Carey, S. W.: Theories of the Earth and Universe: A History of Dogma in the Earth Sciences, Stanford, CA, Stanford University Press, 1988.

Chao, B. F. and Gross, R. S.: Changes in the Earth's rotation and low-degree gravitational field induced by earthquakes, Geophys. J. Roy. Astr. S., 91, 569-596, 1987.

Chen, Z.: The evolution model of the earth's limited expanding, Chinese Sci. Bull., 45, 304-313, 2000.

Collilieux, X. and Altamimi, Z. (Eds.): External evaluation of the origin and scale of the International Terrestrial Reference Frame, 
in: Reference frames for applications in geosciences, International Association of Geodesy Symposia 138, Springer-Verlag, Berlin, 27-31, 2013.

Creer, K. M.: An expanding Earth?, Nature, 205, 539-544, 1965.

Cwojdzinski, S.: Distribution of tectonic stresses within the Earth crust due to expansion of its interior, in: The Earth expansion evidence - A challenge for geology, geophysics and astronomy, edited by: Scalera, G., Boschi, E. and Cwojdzinski, S., INGV, Rome, 29-40, 2003.

Dearnley, R.: Orogenic fold-belts, convection and expansion of the Earth, Nature, 206, 1284-1290, 1965.

Dearnley, R.: Crustal tectonic evidence for Earth expansion, in: The application of modern physics to the Earth and planetary interiors, edited by: Runcorn, S. K., London, Wiley Interscience, 103110, 1969.

Dirac, P. A. M.: The cosmological constants, Nature, 139, p. 323, doi:10.1038/139323a0, 1937.

Drewes, H., Angermann, D., and Seitz, M.: Alternate definitions of the Terrestrial Reference System and its realization in reference frames, in: Reference frames for applications in geosciences, International Association of Geodesy Symposia 138, edited by: Altamimi, Z. and Collilieux, X., Springer-Verlag, Berlin, 39-44, 2013.

Edwards, M. R. (Ed.): Pushing gravity: new perspectives on Le Sage's theory of gravitation, C. Roy Keys Inc., Montreal, 316 pp., 2002.

Edwards, M. R.: Graviton decay without decreasing $G$ : a possible cause of planetary heating, expansion and evolution, Ann. Geophys.-Italy, 49, 501-509, 2006.

Edwards, M. R.: Does the Hubble redshift flip photons and gravitons?, Astrophys. Space Sci. 339, 13-17, 2012a.

Edwards, M. R.: Gravity, cosmology and expanding Earth, in: The Earth expansion evidence - A challenge for geology, geophysics and astronomy, edited by: Scalera, G., Boschi, E., and Cwojdzinski, S., INGV, Rome, 197-211, 2012 b.

Edwards, M. R.: Gravity from refraction of CMB photons using the optical-mechanical analogy in general relativity, Astrophys. Space Sci., 351, 401-406, 2014.

Egyed, L.: Determination of changes in the dimension of the Earth from palæogeographical data, Nature, 173, p. 534, doi:10.1038/178534a0, 1956.

Egyed, L.: The slow expansion hypothesis, in: The application of modern physics to the Earth and planetary interiors, edited by: Runcorn, S. K., London, Wiley-Interscience, 65-75, 1969.

Fairbridge, R. W.: Thoughts about an expanding globe, in: Advancing frontiers in geology and geophysics, edited by: Subramanian, A. P. and Balakrishna, S., Indian Geophysical Union, Hyderabad, 59-88, 1964.

French, S. W. and Romanowicz, B: Broad plumes rooted at the base of Earth's mantle beneath major hotspots, Nature, 525, 95-99, doi:10.1038/nature14876, 2015.

Fukao, Y. and Obayashi, M.: Subducted slabs stagnant above, penetrating through, and trapped below the $660 \mathrm{~km}$ discontinuity, J. Geophys. Res.-Sol. Ea., 118, 5920-5938, 2013.

Hand, E.: Mantle plumes seen rising from Earth's core, Science, 349, 1032-1033, 2015.

Heezen, B. C.: The rift in the ocean floor, Sci. Am., 203, 98-110, 1960.
Hilgenberg, O. C.: Vom wachsenden Erdball (The expanding Earth), Giessman and Bartsch, Berlin, 56 pp., 1933.

Jordan, P.: Geophysical consequences of Dirac's hypothesis, Rev. Mod. Phys., 34, 596-600, 1962.

Jordan, P.: The expanding earth, Pergamon, Oxford (translated and revised from the German edition: Die Expansion der Erde, Friedr. Vieweg, Braunschweig, 1966), 1971.

Kerr, R. A.: The deep Earth machine is coming together, Science, 340, 22-24, 2013.

Koppers, A. A. P.: Mantle plumes persevere, Nat. Geosci., 4, 816817, 2011.

Kragh, H.: Expanding Earth and declining gravity: a chapter in the recent history of geophysics, Hist. Geo Space. Sci., 6, 45-55, doi:10.5194/hgss-6-45-2015, 2015a.

Kragh, H.: Pascual Jordan, varying gravity, and the expanding Earth, Physics Perspectives, 17, 107-134, doi:10.1007/s00016015-0157-9, 2015b.

Kumagai, I., Davaille, A., Kurita, K., and Stutzmann, E.: Mantle plumes: thin, fat, successful or failing? Constraints to explain hot spot volcanism through time and space, Geophys. Res. Lett., 35, L16301, doi:10.1029/2008GL035079, 2008.

Kuzmin, M. I. and Yarmolyuk, V. V.: Plate tectonics and mantle plumes as a basis of deep-seated Earth's tectonic activity for the last 2 Ga, Russ. Geol. Geophys., 57, 8-21, 2016.

Marchal, C.: Earth's polar displacements of large amplitude: a possible mechanism, Bulletin du Museum National d'Histoire Naturelle, Section C: Sciences de la Terre, 4 ser., 18, 517-554, 1996.

Maxlow, J.: Terra non firma Earth: plate tectonics is a myth, Terrella Press, 155 pp., 2005.

Maxlow, J.: Global expansion tectonics: definitive proof, in: The Earth expansion evidence - A challenge for geology, geophysics and astronomy, edited by: Scalera, G., Boschi, E. and Cwojdzinski, S., INGV, Rome, 41-59, 2012.

McCarthy, D.: The trans-Pacific zipper effect: disjunct sister taxa and matching geological outlines that link the Pacific margins, J. Biogeogr., 30, 1545-1561, 2003.

Morgan, W. J.: Convection plumes in the lower mantle, Nature, 230, 42-43, 1971.

Nunan, R.: The theory of an expanding Earth and the acceptability of guiding assumptions, in: Scrutinizing Science: Empirical Studies of Scientific Change, edited by: Donovan, A., Laudan, L., and Laudan, R., Dordrecht, Kluwer Academic, 289-314, 1988.

Owen, H. G.: Continental displacement and expansion of the Earth during the Mesozoic and Cenozoic, Philos. T. Roy. Soc. A, 281, 223-291, 1976.

Owen, H. G.: Atlas of continental displacement, 200 million years to the present, Cambridge University Press, London, 159 pp., 1983.

Pickford, M.: Earth expansion, plate tectonics and Gaia's pulse, Bulletin du Museum National d'Histoire Naturelle, Section C: Sciences de la Terre, 4 ser., 18, 451-516, 1996 a.

Pickford, M.: Earth expansion and plate tectonics: historical review, comparison and discussion, S. Afr. J. Sci., 92, 365-370, 1996 b.

Pickford, M.: The expanding Earth hypothesis: a challenge to plate tectonics, in: Why expanding Earth? A book in honour of O. C. Hilgenberg, edited by: Scalera, G. and Jacob, K.-H., INGV, Rome, 233-242, 2003. 
Piper, J. D. A.: The Precambrian palaeomagnetic record: the case for the Proterozoic Supercontinent, Earth Planet. Sc. Lett., 59, 61-89, 1982.

Piper, J. D. A.: The Neoproterozoic supercontinent: Rodinia or Palaeopangaea?, Earth Planet. Sc. Lett., 176, 131-146, 2001.

Piper, J. D. A.: A planetary perspective on Earth evolution: lid tectonics before plate tectonics, Tectonophysics, 589, 44-56, 2013.

Scalera, G.: Paleogeographical reconstructions compatible with Earth dilatation, Ann. Geophys.-Italy, 41, 819-825, 1998.

Scalera, G.: The expanding Earth: a sound idea for the new millennium, in: Why expanding Earth? A book in honour of $\mathrm{O}$. C. Hilgenberg, edited by: Scalera, G. and Jacob, K.-H., INGV, Rome, 181-232, 2003.

Scalera, G.: TPW and Polar Motion as due to an asymmetrical Earth expansion, Ann. Geophys.-Italy, 49, 483-500, 2006.

Scalera, G. and Braun, T.: Ott Christoph Hilgenberg in twentiethcentury geophysics, in: Why expanding earth? - A book in honour of Ott Christoph Hilgenberg, edited by: Scalera, G. and Jacob, K.-H., INGV, Rome, 25-41, 2003.

Scalera, G. and Jacob, K.-H. (Eds.): Why expanding Earth? A book in honour of O. C. Hilgenberg, INGV, Rome, 465 pp., 2003.

Scalera, G., Boschi, E., and Cwojdzinski, S. (Eds.): The Earth expansion evidence - A challenge for Geology, Geophysics and Astronomy, Selected contributions to the Interdisciplinary Workshop of the 37th International School of Geophysics Erice, Sicily, INGV, Rome, 2012.

Shen, W.-B., Sun, R., Chen, W., Zhang, Z., Li, J., Han, J., and Ding, H.: The expanding Earth at present: evidence from temporal gravity field and space-geodetic data, Ann. Geophys.-Italy, 54, 436-453, doi:10.4401/ag-4951, 2011.

Shen, W.-B., Sun, R., Barkin, Y. V., and Shen, Z.-Y.: Estimation of the asymmetric vertical variation of the southern and northern hemispheres of the Earth, Geodynamics and Tectonophysics, 6, 45-61, doi:10.5800/GT-2015-6-1-0171, 2015a.

Shen, W., Shen, Z., Sun, R., and Barkin, Y.: Evidences of the expanding Earth from space-geodetic data over solid land and sea level rise in recent two decades, Geodesy and Geodynamics, 10, 1-5, doi:10.1016/j.geog.2015.05.006, 2015b.

Shneiderov, A. J.: The exponential law of gravitation and its effects on seismological and tectonic phenomena: a preliminary exposition, Transactions of the American Geophysical Union, 61-88, 1943.
Shneiderov, A. J.: On the internal temperature of the earth, B. Geofis. Teor. Appl., 3, 137-159, 1961.

Sudiro, P.: The Earth expansion theory and its transition from scientific hypothesis to pseudoscientific belief, Hist. Geo Space. Sci., 5, 135-148, doi:10.5194/hgss-5-135-2014, 2014.

Uzan, J.-P.: The fundamental constants and their variation: Observational status and theoretical motivations, Rev. Mod. Phys., 75 , 403-459, 2003.

Vogel, K.: Contributions to the question of Earth expansion based on globe-models, in: The Earth expansion evidence - A challenge for geology, geophysics and astronomy, edited by: Scalera, G., Boschi, E., and Cwojdzinski, S., INGV, Rome, 161-170, 2012.

Weijermars, R.: Slow but not fast global expansion may explain the surface dichotomy of Earth, Phys. Earth Planet. In., 43, 67-89, 1986.

Wesson, P. S.: Cosmology and geophysics, Oxford University Press, Oxford, 240 pp., 1978.

Wesson, P. S.: Gravity, particles and astrophysics, D. Reidel Publishing Co., 186 pp., Dordrecht, 1980.

Williams, G. E.: Geological constraints on the Precambrian history of Earth's rotation and the Moon's orbit, Rev. Geophys., 38, 37$59,2000$.

Wu, X., Collilieux, X., Altamimi, Z., Vermeersen, B., Gross, R. S., and Fukumori, I.: Accuracy of the International Terrestrial Reference Frame origin and Earth expansion, Geophys. Res. Lett., 38, L13304, doi:10.1029/2011GL047450, 2011.

$\mathrm{Xu}, \mathrm{C}$. and Sun, W.: Earthquake-origin expansion of the Earth inferred from a spherical-Earth elastic dislocation theory, Geophys. J. Int., 199, 1655-1661, 2014.

Xu, C., Wei, D., and Sun, W.: Contribution of coseismic deformations on the current expansion of the Earth, J. Geodynamics, 99, 10-15, doi:10.1016/j.jog.2016.05.001, 2016.

Yarkovskii, I. O.: Vsemirnoe tyagotenie kak sledstvie obrazovaniya vesomoi materii vnutri nebesnykh tel (Universal Gravitation as a Consequence of the Generation of Gravitating Matter inside Celestial Bodies), Tipolitografiya tovarishchestva I. N. Kushner, Moscow, 1889.

Zhao, D.: Seismic images under 60 hotspots: search for mantle plumes, Gondwana Res., 12, 335-355, 2007. 